\title{
SHARPENING OF THERMAL SATELLITE IMAGERY FROM KLANG INDUSTRIAL AREA IN PENINSULAR MALAYSIA USING THE TSHARP APPROACH
}

\author{
M. Z. Dahiru 1,2,3, Mazlan Hashim ${ }^{1,2 *}$, NoorDyana Hassan ${ }^{1,2}$ \\ ${ }^{1}$ Geoscience \& Digital Earth Centre (INSTEG), Research Institute for Sustainable Environment (RISE), Universiti Teknologi \\ Malaysia, Johor Bahru, Malaysia \\ ${ }^{2}$ Faculty of Geoinformation \& Real Estate, Universiti Teknologi Malaysia, Johor Bahru. \\ ${ }^{3}$ Adamawa State Polytechnic, Yola. Adamawa State Nigeria \\ *E-Mail: mazlanhashim@utm.my \\ Commission 4, WG 7
}

KEYWORDS: Remote sensing, Heat emission, downscaling, split-window algorithm, Indicators (NDVI, NSVI and NDBI)

\begin{abstract}
Measuring high spatial/temporal industrial heat emission (IHE) is an important step in industrial climate studies. The availability of MODIS data products provides up endless possibilities for both large-area and long-term study. nevertheless, inadequate for monitoring industrial areas. Thus, Thermal sharpening is a common method for obtaining thermal images with higher spatial resolution regularly. In this study, the efficiency of the TsHARP technique for improving the low resolution of the MODIS data product was investigated using Landsat-8 TIR images over the Klang Industrial area in Peninsular Malaysia (PM). When compared to UAV TIR fine thermal images, sharpening resulted in mean absolute differences of about $25^{\circ} \mathrm{C}$, with discrepancies increasing as the difference between the ambient and target resolutions increased. To estimate IHE, the related factors (normalized) industrial area index as NDBI, NDSI, and NDVI were examined. The results indicate that IHE has a substantial positive correlation with NDBI and NDSI $\left(\mathrm{R}^{2}=0.88\right.$ and 0.95 , respectively), but IHE and NDVI have a strong negative correlation $\left(\mathrm{R}^{2}=0.87\right)$. The results showed that MODIS LST at $1000 \mathrm{~m}$ resolution can be improved to $100 \mathrm{~m}$ with a significant correlation $\mathrm{R}^{2}=0.84$ and RMSE of $2.38{ }^{\circ} \mathrm{C}$ using Landsat 8 TIR images at 30 $\mathrm{m}$, and MODIS LST at $1000 \mathrm{~m}$ resolution can still be improved to $100 \mathrm{~m}$ with significant correlation $\mathrm{R}^{2}=0.89$ and $\mathrm{RMSE}$ of $2.06{ }^{\circ} \mathrm{C}$ using aggregated Landsat- 8 TIR at $100 \mathrm{~m}$ resolution. Similarly, Landsat- 8 TIR at $100 \mathrm{~m}$ resolution was still improved to $30 \mathrm{~m}$ and used with aggregate UAV TIR at $5 \mathrm{~m}$ resolution with a significant correlation $\mathrm{R}^{2}=0.92$ and RMSE of $1.38{ }^{\circ} \mathrm{C}$. Variation has been proven to have a significant impact on the accuracy of the model used. This result is consistent with earlier studies that utilized NDBI as a downscaling factor in addition to NDVI and other spectral indices and achieved lower RMSE than techniques that simply used NDVI. As a result, it is suggested that the derived IHE map is suitable for analyzing industrial thermal environments at 1:10,000 50,000 scales, and may therefore be used to assess the environmental effect.
\end{abstract}

\section{INTRODUCTION}

Heat loss is an important environmental variable and measure of air quality (Veefkind et al., 2007; Energy, 2008; Rani et al., 2018). the influence of energy loss in economic sectors and vigorous waste heat loss from industrial plants have substantial implications for human health and climate change (Vollrath, 1987). Therefore, various phenomena such as urban up-to-date, forest fire, and more recently industrial related thermal objects have become issues of concern. Hence, to understand the dynamics of energy loss, industrial heat emission (IHE) should be holistically comprehended as it is considered as one of the most significant physicalenvironmental variables (Huo et al., 2014; Yao et al., 2019).

Currently, in an epoch of technological revolution, progress in data acquisition is quite crucial and remained relevant in the thermal domain. However, the influence of energy loss in economic sectors and vigorous waste heat loss from industrial plants for many possible applications such as industrial inspection (Nikolic et al., 2013; Baena et al., 2017; Boesch, 2017), environmental monitoring (Turner et al., 2014; Chmaj and Selvaraj, 2015; Harvey et al., 2016;
Torres-rua and Hipps, 2019), have substantial implications for human health and climate change (Vollath, 1987).

Thermal imagine is an authoritative means for exploding the thermal information used to repossess Surface Temperature (ST) (Ferrari et al., 2020). The cognition of the ST is an indicator that can offer valuable data from various geophysical environmental applications (geological studies, mineral exploration, and evapotranspiration) (Tan et al., 2017; Dahiru and Hashim, 2020) $[2,3]$. Consequently, The advancement in remote sensing technology offers an opportunity to provide a reliable, consistent, and repeatable approach within the working frame from local to a global scale, as well as long-term monitoring of oil spillage operations (Bromley et al., 2015; Casagli et al., 2017) The development and changes related to land cover and urban features have been associated with industrial heat emission, where the surface air temperature is becoming higher compared to the surrounding environment (Lee et al., 2003). There is a need for industrial heat regulations which will attach to green space to monitor the heat intensity from industrial heat emissions through a 
descriptive technology (Liu et al., 2018; Zhang et al., 2019) In connection with ground truth measurement of air temperature (Takebayashi, 2017).

Therefore, the study of ST contributes to identifying the extent of high temperature from the thermal information over the different urban land cover boundary which is limited to a comparatively small area in which concurrently measured air temperature through the full stretch. Thus, the remotely sensitive approach for ST offered an option to capture the relatively small area as well as a larger area. However, the special solution for such datasets which ranging from $60 \mathrm{~m}$ to $100 \mathrm{~m}$ TIRS and $<1 \mathrm{~m}$ UAV TIRs is insufficient to capture a large lot of industries that emit heat concerning heterogeneous ground features (Zawadzka, et al., 2019). Established in the preview literature on prominent research, downscaling studies of coarse spatial resolution LST of the developed areas were relatively targeted with final downscaling special resolution comprising $1000 \mathrm{~m}$, 480120m, 6m-90m, 50m, and 30m (Sharma et al., no date; Jos et al., 2018; Wu et al., 2019) with downscaling factors, recently attempt on downscaling to $2 \mathrm{~m}$ special resolution. The spatiotemporal trends of LST are investigated and contrasted using several indices such as NDVI, NDBI, and the Normalized Difference Water Index (NDWI). The modern benefit of this research was the application of remote sensing data in broader issues concerning the effects of IHE on the industrial surrounding and human health.

In this paper, we apply high and medium resolution data from Landsat 8 TIR bands (10 and 11) to generate heat emission image

\section{STUDY AREA}

The study was conducted in the industrial district of Klang in the Selangor state of Peninsular Malaysia $\left(2^{\circ} 59^{\prime} \mathrm{N}, 101^{\circ} 20^{\prime} \mathrm{E}\right)$ in 2020 as shown in Figure 1. The Pulau Indah $\left(456,379.90 \mathrm{~m}^{2}\right)$ is multi-industry parks of heavy, light, and simple that some operate $24 \mathrm{hrs}$. The area was predominantly a tropical climate zone that lies within $5 \mathrm{~m}$ above the datum surface with a significant amount of rainfalls with an ordinary temperature of about $26.8^{\circ} \mathrm{C} / 80.3^{\circ} \mathrm{F}$.

The area was predominantly a tropical climate zone at an elevation of $5 \mathrm{~m}$ with a mean rainfall of $2208 \mathrm{~mm}$ with a daily temperature range of $27 \sim 32{ }^{\circ} \mathrm{C}$. In the highlands, the temperature is lower and ranges from $16^{\circ} \mathrm{C}$ to $24^{\circ} \mathrm{C}$ as defined by (Syafrina et al., 2015; Tang, 2019). Peninsular Malaysia is considered to be an area where waste heat loss can occur due to its proximity to many industries in the state (Energy Commission, 2017; Goleman et al., 2019). The major energy sources include primary fuel gas and secondary fuel for Pulau Indah industrial area based on the relationship with MODIS product data, which is the technique for multiple adaptive regression splines (MARS) was tested to suit diverse regression function into different n-dimensional data (Mukherjee et al., 2015). Nevertheless, the MARS techniques predict the special distribution of environmental activities, mostly limited to soil mapping (Piikki and Söderström, 2019) and landslide detection (Wang et al. 2015). Therefore, we undertake to use MARS in heat emission downscaling for the industrial area of Pasir Gudang. The objectives of this study present as follow; (i) To explore the techniques for downscaling spatial resolution images for both UAV and Landsat8 TIRS for enhancing the accuracy of the downscaled map (ii) to investigate the sensitivity of Landsat- 8 TIR for detecting industrial thermal energy heat emission within various range of targets for different temperatures (iii) and to evaluate the link between the industrial material and thermal energy at microscales (1:10,000 50,000 scales) (Burdun et al., 2019; Zawadzka, Corstanje, Harris, Truckell, et al., 2019; Dahiru and Hashim, 2020). Therefore, the potential of the Multivariate Adaptive Regression Splines model is suitable for study industrial thermal energy for impact assessment. Therefore, detecting, mapping, and monitoring industrial heat energy sources to support understanding toward improving disparities on existing industrial substances for policymaker's implementation.

About $2208 \mathrm{~mm} / 86.9$ inch of precipitation during the twelvemonth. Figure 1. Shown the location of the industrial sites. Though, considering the study location which is relatively small in size, the altitude, and the satisfactory climatic conditions during the flight campaign, the atmospheric corrections were neglected during the flight. Pulau Industrial area is one of the populous industrial parks located in the Klang area was established in 1994 with the hope to improve the economic sectors of Malaysia.

oil, which is recognized as the biggest gas turbine power station in Malaysia. The temperature of the study area is influenced by the two main seasons; Winter period (Northeast monsoon) brings heavy rainfall mostly to the east coast states during November to March, and the Summer period (Southwest monsoon) signifies relatively drier weather during May to September (At et al., 2015). 


\section{2'30"E $\quad 103^{\circ} 55^{\prime} 0^{\prime \prime E} \quad 103^{\circ} 57^{\prime} 30^{\prime \prime E} \quad 104^{\circ} 0^{\prime} 0^{\prime \prime E} \quad 104^{\circ} 2^{\prime} 30^{\prime \prime E}$}
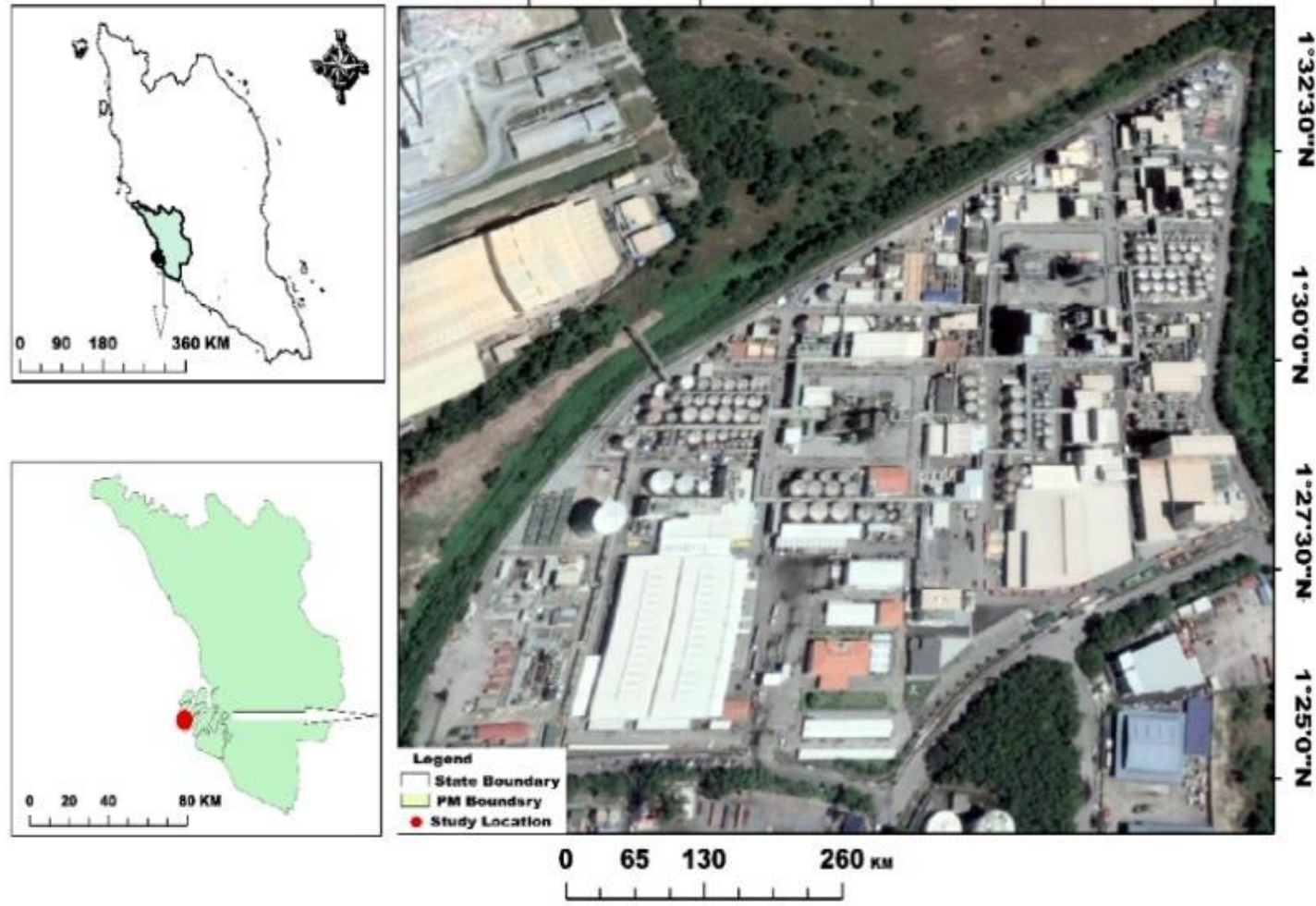

Figure 1. Studies at Pulau Indah, Klang District, Selangor, Peninsular Malaysia.

\section{Material and Method}

In this study, satellite-based data from Landsat-8 TIR and MODIS LST products shown in (Table 1) was acquired. The satellite data acquired from the Landsat-8 OLI/TIR sensor were subset to limit the data size. The preprocessing stage included geometrically and radiometrically corrected in the datum WGS84 and projection UTM zone N48 using the first order (linear) of the polynomial function. The thermal infrared band (band 10 and 11) image has a spatial resolution of $100 \mathrm{~m}$ which was resampled using the nearest neighbour algorithm with a pixel size of $30 \mathrm{~m}$ to match the optical bands, which was chosen to preserve the radiometry and spectral information in the imagery. These images have a spatial resolution of 30 meters per pixel to enhance the image quality. Landsat 8 data consisted of independent distinct band images which were the first layer stacked and combined into a multi-band image. To analyse the changes in temperature in the study area, The OLI/TIRS data for red, near-infrared, and middle infrared bands (bands 4, 5, and 6) have been used for the estimate of the Normalized Difference Vegetation Index (NDVI), Normalized Difference Built-up Index (NDBI), Normalized Differential Water Index (NDWI) while thermal bands (bands 10 and 11) were used for retrieval of the correlation with derived IHE for 21st February 2020. through implementing the SW algorithm, we have described the entire method of extracting these features from satellite data using ArcGIS software in the subsequent sentences, and finally, the statistical analysis was carried out using the empirical regression analysis function.

Table 1. Specification of the data used in the study.

\begin{tabular}{|c|c|c|c|c|}
\hline Sensors & Bands & SR & Path/Row & Date \\
\hline TIR band $(10 \& 11)$ & $\begin{array}{l}\text { TIRS bands }(10,11) \\
\text { OLI }(5,4)\end{array}$ & $100 \mathrm{~m}$ & $125 / 59$ & $21 / 2 / 2020$ \\
\hline MODIS/MOD11B2 & TIRS bands $(31,32)$ & $1000 \mathrm{~m}$ & MOD21_L2 Terra & $10 / 02 / 2020$ \\
\hline UAV & Parrot Anafithermal & FLIR & & $20 / 01 / 2020$ \\
\hline
\end{tabular}




\subsection{Analysis of NDVI, NDSI and NDBI}

The terms NDVI and NDBI relate to vegetation and constructed area indicators that are widely used to explore the correlation between LST, vegetation, and constructed areas (Guha et al., 2018)(Jamei et al., 2019). Because of its benefits, such as high sensitivity to chlorophyll and noise reduction by normalization between -1 and +1 , NDVI is widely used. However, this index has drawbacks, such as a high sensitivity to vegetation changes. Besides it as well, NDBI was developed by (Zha et al., 2003) to analyze the reflectance changes on TM 5 bands 4 and 5 for images of urbanized and barren land areas NDBI (Zhao and Chen, 2005) is considered as a significant variable and indicator of LST. The NDBI is highly scalable from -1 to 1 . Positive numbers reflect densely urbanized areas, while negative values represent other forms of land cover.

The NDVI (Kumari et al., 2018)(Mia et al., 2017) was employed in this study since it is the most effective and frequently used indicator for vegetation extraction. In this investigation, NDBI (Guha et al., 2018)(Jamei et al., 2019)(Gillani et al., 2019)values ranging from -1 to 1 were used to detect the industrial area. These

Where, MIR is middle infrared reflectance, which is band 6 of Landsat-8, Red is band 4 for Landsat-8; NDBI values (Guha et al., 2018; Gillani et al., 2019; Jamei et al., 2019) range from -1 to 1. The greater the NDBI is, the higher the proportion of the builtup area

According to combines, vegetation and water bodies may be easily retrieved based on the spectral variations. The normalized difference soil index (NDSI) can then be used to differentiate bare areas, including main bare land, supplementary bare land, and agricultural areas, from other surface covers, particularly constructed areas and wetlands, which had similar spectral reflectance but were not classified in the spectral profiles. The normalized difference soil index is defined as:

$$
N D S I=\frac{(\text { band } 6-\text { band } 5)}{(\text { band } 6+\text { band } 5)}
$$

wherein band 5 and band 6 indicate the reflectance of band 5 and band 6 , respectively, because only soil is more reflective in band 6 than band 5.Landsat-8 OLI/TIR data (Wulder et al., 2019).

The Normalized Difference Vegetation Indicator (NDVI) is a vegetation index that is frequently used to measure the spatial extent and health of vegetation in a given area. It is frequently used to examine a spectral band in the near-infrared wavelength and

\subsection{Conversion of digital number (DN) to radiance}

The top of atmospheric (TOA) of the OLI band (2-7) and TIRS sensor band (10 and 11) are estimated separately. The sensor converts a raw image into the spectral radiance, the Equ.5 is realized using ArcGIS 10.5 software package

$$
L_{\lambda}=M_{L} \times \varphi_{c a l}+A_{L}-Q_{i}
$$

two indices may be used to classify different sorts of Land data using appropriate threshold values (Khandelwal et al., 2018)(Shumilo et al., 2019). On the spectral bands of the indices, multispectral bands operators were utilized to achieve more reliable classification. For instance, NDVI $>0.2$ and NDBI 0 can be combined to extract vegetation (Malik et al., 2019). Likewise, NDVI 0 and NDBI 0 can be used to retrieve water bodies, while 0 NDVI 0.2 and NDBI > 0.1 can be used to extract built-up area and bare land (Kumari et al., 2018)(Kumari et al., 2018). However, owing to atmospheric circumstances, these threshold values may differ.

The NDBI is a widely used index for mapping urban and rural regions. The reflectance of built-up regions increases dramatically in the Shortwave Infrared (SWIR) wavelength range (1.55-1.75) $\mathrm{m}$ and decreases dramatically in the Near Infrared (NIR) wavelength range (0.76-0.90) $\mu \mathrm{m}$. Built-up pixels have positive values as a result of the difference between these two wavelength ranges (Malik et al., 2019) as follows:

$$
N D B I=\frac{M I R(\text { band } 6)-R(\text { band } 4)}{M I R(\text { band } 6)+R(\text { band } 4)}
$$

another in the red wavelength (Kumari et al., 2018)(Mia et al., 2017). NDVI was computed in ArcGIS software using NIR Band 5 and Red Band 4 data from Landsat- 8 using Equation 2. The NIR and red band used to estimate the NDVI values: This study realized the NDVI for soil as $-0.0002\left(\mathrm{NDVI}_{\min }\right)$, while for vegetation as 0.4744 (NDVI $I_{\max }$ ).

$$
\text { NDVI }=\frac{\mathrm{NIR}(\text { band5 })-\mathrm{R}(\text { band4) }}{\mathrm{NIR}(\text { band5 })+\mathrm{R}(\text { band })}
$$

The Normalized Differential Water Index (NDWI) was employed to monitor the state of soil moisture and water bodies in the research area. The ratio of Band $3(\mathrm{R})$ to Band 5 (short-wave infrared (SWIR): 1.55-1.75 $\mu \mathrm{m}$ ). Water bodies were enhanced in the spectral area, resulting in brighter pixels (Rogers and Kearney, 2004)(Fadhil, 2011).

$$
N D W I=\frac{\operatorname{Red}(\text { Band } 4)-S W I R(\text { band } 6)}{\operatorname{Red}(\text { Band } 4)+S W I R(\text { band } 6)}
$$

Various mathematical techniques were utilized and processed in ArcGIS software to estimate IHE from Landsat-8 satellite data. The following stages are involved in the evaluation of IHE from thermal bands in ArcGIS raster processing:

where, $\mathrm{L}_{\lambda}$ is the TOA spectral radiance (watts $/\left(m^{2} \operatorname{srad} * \mu \mathrm{m}\right)$ ) ; $M_{L}$ - band-specific multiplicative rescaling factor obtained from the metadata Table 3 (Barsi et al., 2014).

\subsection{Conversion to At-Satellite Brightness temperature (BT)}

BT is the electromagnetic radiance moving upward from the top of the earth's atmosphere to allow the thermal calibration conversion (The DN values of TIR band 10 and 11 to TOA spectral radiance), 
(USGS Handbook, 2013) Equ.6. therefore, The BT is not a temperature on the ground rather is the temperature at the satellite.

$$
T_{B}=K_{2} / \operatorname{Ln}\left[\left(\frac{K_{1}}{L_{\lambda}}\right)+1\right]^{-273.15}
$$

\subsection{Heat Emissivity}

Accurate Industrial heat emission (IHE) estimation from TIR bands (10 and 11) relies on atmospheric effect features with adequate knowledge of LSE (Smith, 1997). The LSE and ambient temperature are two substantial variables used to identified land surface processes and charge of radiation budget. Therefore, in this paper, the NDVI-based emissivity process was implemented to estimate the NDVI derived from TIR bands (10 and 11) data. The NDVI was categorized into bare soil $(N D V I<0.2)$, mixture of bare soil and vegetation $(0.2 \leq N D V I \leq 0.5)$, and fully vegetation $(N D V I>0.5)$, each of these classes is estimating using the following equation $[27,28]$.

\subsection{Industrial heat emission (IHE) Retrieval}

The IHE can be retrieved using the SW algorithm developed by (Jimenez-Munoz et al., 2014) for Landsat -8 TIRS. According to (Ren et al., 2014), the Split-Window methods use two TIRs bands classically located in the atmospheric window between 10 and $12 \mu \mathrm{m}$, The mathematical structure for estimating the LST Landsat 8 can be articulated as [25, 28], expressed in Equ (9): Where $\mathrm{T}_{\mathrm{S}}$ is given as; where: $T_{B}$ - At satellite brightness temperature $(\mathrm{K}) ; K_{1}$-Calibration constant 1 (watts $/\left(\mathrm{m}^{2} \mathrm{srad} * \mu \mathrm{m}\right) ; K_{2}$-Calibration constants 2 , However, the values are in Kelvin (K), to have it in Celsius degree, it is necessary to consider by adding absolute zero which is equal to -273.15 .

$$
\begin{aligned}
& \mathrm{FVC}=\left[\frac{\left(N D V I-N D V I_{\text {min }}\right)}{\left(N D V I_{\text {max }}-N D V I_{\text {min }}\right)}\right]^{2} \\
& \varepsilon_{\lambda}=\varepsilon_{v \lambda} F V C+\varepsilon_{s \lambda}(1-F V C)+C_{\lambda}
\end{aligned}
$$

Where; $\varepsilon_{s}$ and $\varepsilon_{v}$ represent the emissivity of vegetation and soil respectively, FVC represent proportional vegetation, and $\mathrm{C}$ represents the surface roughness with a constant value of 0.005 (Algorithms et al., 2020).

$$
\begin{aligned}
& T_{B 10}+c_{1}\left(T_{B 10}-T_{B 11}\right)+c_{2}\left(T_{B 10}-T_{11}\right)^{2}+\cdots \\
& +c_{0}+\left(c_{3}+c_{4} w\right)(1-\varepsilon)+\left(c_{5}+c_{6} w\right) \Delta \varepsilon
\end{aligned}
$$

$T_{S}$ is given as Land surface Temperature; $T_{B 10}, T_{B 11}$ are the Brightness temperature of band 10 and 11 of Landsat -8 ; TIRS W is the atmospheric water vapour contents $\left(\mathrm{g} / \mathrm{cm}^{2}\right) . \varepsilon$ mean emissivity; $\Delta \varepsilon$ emissivity differences; $c_{0}$ to $c_{6^{-}}$is the $\mathrm{SW}$ coefficient values. The coefficient values for SW were shown in Table $2[32,33]$.

Table 2: SW coefficients values for TIRS bands of Landsat-8 imagery.

\begin{tabular}{lccccccc}
\hline Constants & $c_{0}$ & $c_{1}$ & $c_{2}$ & $c_{3}$ & $c_{4}$ & $c_{5}$ & $c_{6}$ \\
\hline Value & -0.268 & 1.378 & 0.183 & 54.300 & -2.238 & -129.200 & 16.400 \\
\hline
\end{tabular}

\subsection{Spatial downscaling and upscaling Techniques}

The majority of geostationary satellite products for global and regional monitoring have a high temporal resolution but a low spatial resolution (Zawadzka, Corstanje, Harris and Truckell, 2019)(Zhao et al., 2019). Satellite-derived products have an insufficient spatial resolution for comprehensive local analysis.
High spatial resolution products, on the other hand, are rarely accessible the disparity in information content supplied by satellite data with varying spatial resolutions. The quantity of thermal information reduces as spatial resolution lowers. As a result, an increase in spatial resolution is frequently necessary to effectively exploit thermal data with a high temporal resolution for environmental monitoring (Wang et al., 2004). 


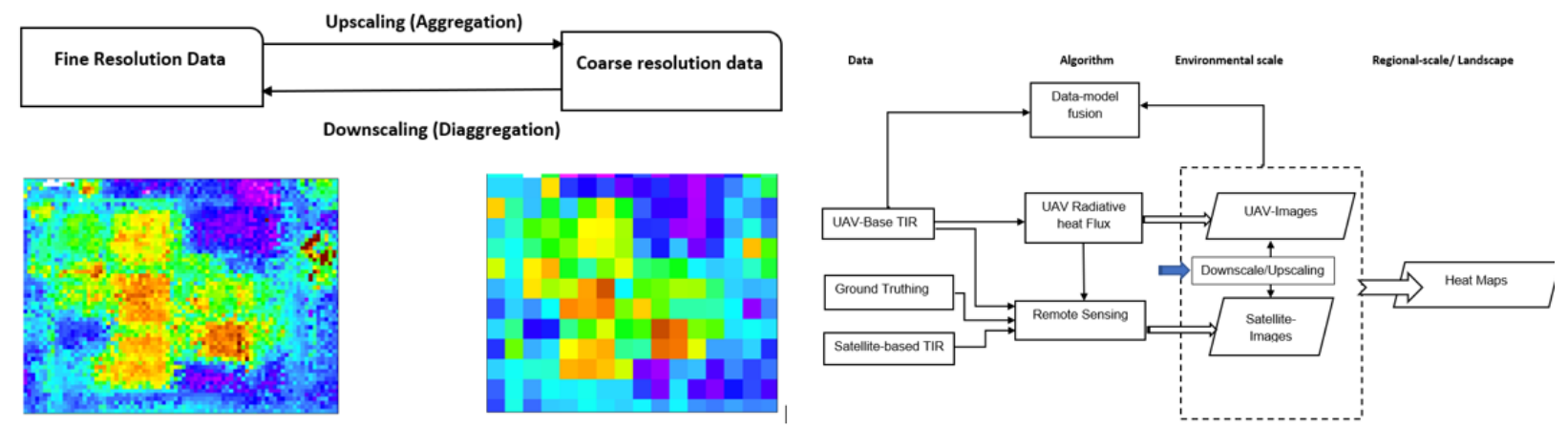

Figure 2. Methodological flowchart.

This technique, though, invariably results in the loss of fine-scale information. As a result, fine-resolution spatial data must also be produced for integrated analysis of multi-sensor/source spatial data sets. Spatial downscaling, also known as disaggregation, is a scale conversion technique that improves spatial resolution (Zawadzka, et al., 2019). whereas a reduction in spatial resolution is referred to as spatial upscaling or aggregation Equ.10. As a result, thermal sharpening techniques are developed to sharpen TIR images to pixel resolutions in the shortwave band, which are frequently fine enough according to field-scale applications. TsHARP, a wellknown thermal sharpening approach, employs a connection between LST and the NDVI, which was empirically derived at the TIR pixel resolution and utilized at the NDVI pixel resolution.

The algorithm for both high and low-resolution satellite data is based on the negative relationship between temperature and NDVI. Over second-order polynomial regression, the downscaling model operated as:

The disTrad ${ }^{\mathrm{RM}}$ model is based on both linear and quadratic terms of the NDVI (Kustas et al., 2003)

$\overparen{H E}=a+b \times N D V I+c \times N D V I^{2}$

This model is an alteration of the DisTrad algorithm. This model operates a simple least-square (LS) regression function in

\subsection{Verification of the results}

As a result of the inaccessibility of different IHE, the downscaled map was validated using the retrieved Landsat- 8 TIR bands. Consequently, the developed models were proved by adjusted $\mathrm{R}^{2}$ at the same calculate the RMSE between the derived TIRS data and downscaled IHE map, RMSE was calculated in two approaches. Firstly, RMSE $2 / 4 \mathrm{~m}$ was calculated from two differences between the observed $\mathrm{IHE}_{30(100) \mathrm{m}}$, resampled to $30 \mathrm{~m}$ spatial resolution with the nearest neighbour method to enable the calculation presented in equation 7 and download map LST MARS2/4m (Zawadzka, et al., 2019). preference to $S L_{s r}$. The fractional vegetation cover (FC) has been used in place of the conventional NDVI approach. The polynomial function has been found more responsive to outliers compared to the simple LS. The present study uses both NDVI and FC as a covariate function with the LST. The TsHARP model Equation (ab) given.

Polynomial fit

$I H E=a+b \times N D V I+c \times N D V I^{2}$

Fc transformation

$$
I H E=a+b\left[1-\left(\frac{N D V I_{\max }-N D V I}{N D V I_{\max }-N D V I_{\min }}\right)^{0.625}\right]
$$

Simplified fc transformation

$$
I H E=a-b(1-N D V I)^{0.625}
$$

In the case of fine spectral resolution, the medium-resolution regression coefficient was applied, to improve the accuracy, adding the residual error of the corresponding medium-resolution images.

$$
R M S E=\sqrt{\frac{1}{N}} \sum_{i=1}^{N}\left(I H E_{\text {sharp }}-I H E_{r e f}\right)^{2}
$$

Therefore, $R M S E_{2 / 4 m}$ was calculated an evaluation between Landsat 8 derived map and downscaled map adjusted for residual $\left(\Delta I H E_{\text {shape }}\right)$ map $I H E_{\text {ref }}^{\prime}$. Equa. (14)

$$
\begin{aligned}
& R M S E^{\prime}=\sqrt{\frac{1}{N}} \sum_{i=1}^{N}\left(I H E_{\text {shape }}-I H E_{\text {ref }}^{\prime}\right)^{2} \\
& R^{2}=\frac{\sum\left(I H E_{\text {sharp }}-I H E_{\text {ref }}\right)^{2}}{\sum\left(I H E_{\text {sharp }}-I H E_{\text {ref-mean }}\right)^{2}}
\end{aligned}
$$




\section{RESULT AND DISCUSSION}

\subsection{Analysis of the IHE, HSE, HBE, and NDVI, NDSI and NDBI relationship}

Table 2 shows the descriptive statistics of IHE for both cities based on NDVI, NDSI, and NDBI values. The IHE distribution was categorized into acceptable ranges and a colour scheme to generate a heating trend distribution map of heat emission over the studied area (Figure 3). The mean IHE values for Pulau Indah industrial are
$50.97{ }^{\circ} \mathrm{C}, 51.78{ }^{\circ} \mathrm{C}$, and $52.565^{\circ} \mathrm{C}$, respectively. The temperature increase threshold values for Pulau Indah industrial are $58.38^{\circ} \mathrm{C}$, $59.43{ }^{\circ} \mathrm{C}$, and $60.02{ }^{\circ} \mathrm{C}$, respectively. Because of the land use/cover changes, there was some variability in the surrounding area. The high rate of activity in the industrial sector, as well as energy generation, has increased the mean IHE. The mean NDVI, NDSI and NDBI values for Pulau Indah are $0.32,0.044$, and -0.0259 , respectively. The study area has the nearly same range of statistical data for IHE, NDVI, and NDBI.
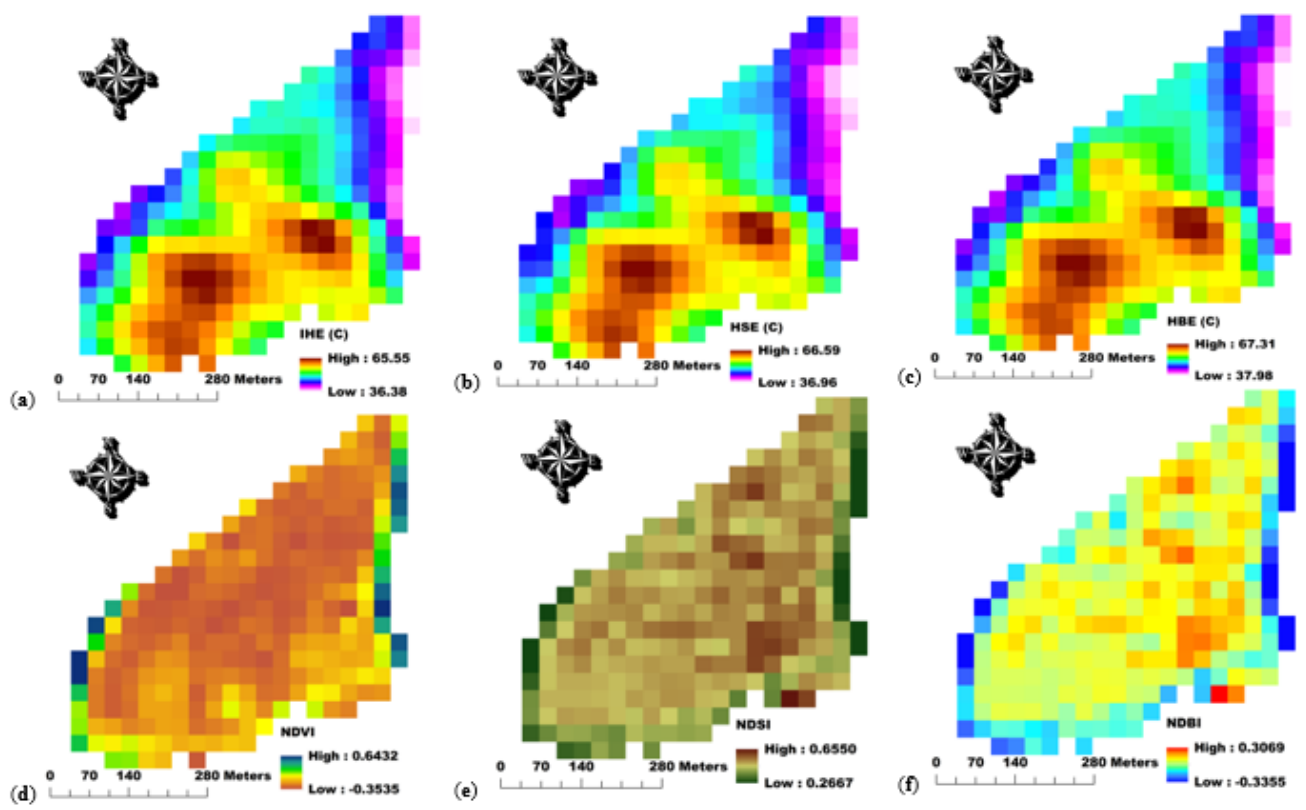

Figure 3. (a - f) Spatio-temporal disparities in NDVI, NDBI, NDSI and IHE $\left({ }^{\circ} \mathrm{C}\right)$

Table 3. Spatial Descriptive statistics of heat emission and corresponding factors (normalized)

\begin{tabular}{lrrll}
\hline $\left.\mathbf{C}^{\circ}\right)$ & \multicolumn{1}{l}{ Min } & \multicolumn{1}{l}{ Mean } & \multicolumn{1}{l}{ Max } & \multicolumn{1}{l}{ Std } \\
IHE & 36.38 & 50.97 & 65.55 & \pm 2.14 \\
SHE & 36.96 & 51.78 & 66.59 & \pm 2.07 \\
HBE & 37.98 & 52.65 & 67.31 & \pm 2.01 \\
\hline \multicolumn{5}{l}{} \\
\hline Indices & \multicolumn{1}{l}{ Min } & Mean & Max & Std \\
NDVI & -0.3535 & 0.3232 & 0.6432 & \pm 0.15 \\
NDSI & -0.2667 & 0.0444 & 0.3555 & \pm 0.06 \\
NDBI & -0.3355 & -0.0259 & 0.3096 & \pm 0.09 \\
\hline
\end{tabular}

\begin{tabular}{|c|c|c|c|}
\hline \multirow{2}{*}{$\begin{array}{l}\text { Classes } \\
\text { (Hu and } X u, 2019)\end{array}$} & \multirow{2}{*}{\multicolumn{2}{|c|}{ NDS! }} & \multirow[b]{2}{*}{ NDBI } \\
\hline & & & \\
\hline Poor $(0.0-0.2)$ & $-0.3535-0.2054$ & $0.5728-0.6551$ & $0.4003-0.5774$ \\
\hline Fair $(0.2-0.4)$ & $0.2054-0.3227$ & $0.5363-0.5728$ & $0.3658-0.4003$ \\
\hline Moderate $(0.4-0.6)$ & $0.3227-0.4281$ & $0.4860-0.5363$ & $0.3355-0.3658$ \\
\hline Good $(0.6-0.8)$ & $0.4281-0.6432$ & $0.3901-0.4860$ & $0.3096-0.3355$ \\
\hline Excellent $(0.8-1.0)$ & -- & $0.2667-0.3901$ & $-0.3355-0.3096$ \\
\hline
\end{tabular}

NDBI and IHE relationships were generated and proven to have a clear correlation during the study. The highest surface temperature from industrial areas was shown by NDBI results. As a result, it has been anticipated that the industrial area will cause significant changes in heat emission. As presented in Figure 5, the NDBI and IHE correlations had a significant positive relationship, with R2 values of 0.98 , 0.97, and 0.95. (a-c). The strong relation established between NDBI and IHE indicates that the built-up area produces a lot of surface heat variability and is a significant contribution to the industrial environment. Healthy vegetative cover, on the other hand, plays a major role in lowering the surface temperature. Table 4 provides summary statistics on NDBI. NDVI is extremely sensitive to changes, and changes in NDVI may induce changes in land surface temperature. Correlation analysis was performed to identify the correlation between IHE and NDVI, which revealed a significant negative correlation $(\mathrm{R} 2=0.87)$, and IHE with NDSI and NDBI, which revealed a strong negative 
correlation $(\mathrm{R} 2=0.87)$. Figure $5(\mathrm{c}-\mathrm{d})$. According to our results, high surface temperatures were observed in industrial areas, surrounding constructions, and bare surfaces, but low surface temperatures were observed in green areas. Table 4 provides statistics. During the study, a relationship between NDVI and NBDI was also established.
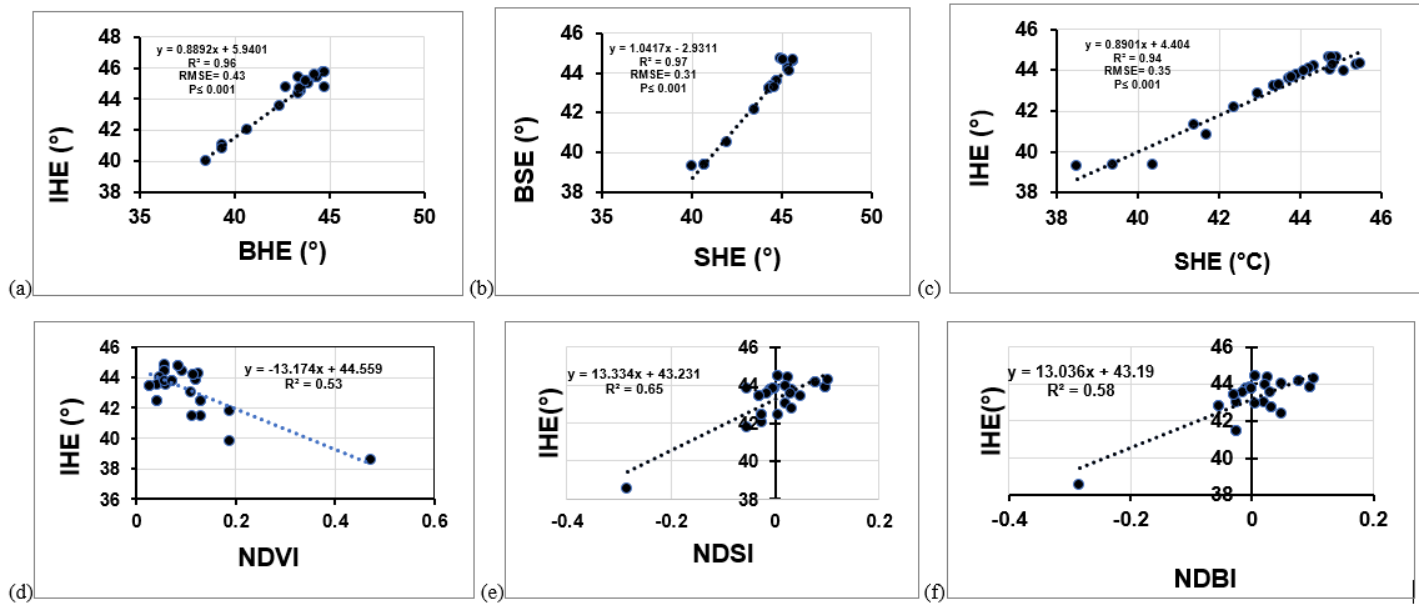

Figure 4. (a) Scattered plots of IHE vs NDVI (b) IHE vs NDBI (b) IHE vs NDSI (d) IHE vs NDVI (e) IHE vs NDSI (f) IHE vs NDBI

\subsection{Validation of IHE generated from MODIS data}

Validation of derived IHE using in situ measurement or another sort of satellite sensor is essential before executing any kind of application process. MODIS data were applied as a reference image in this study to validate the IHE results. MODIS and Landsat- 8 do not exhibit enhanced images of the research region promptly. Thus, MOD11B2 data (1000 m resolution) from 10 February 2020 were used instead of 20 January 2020 for Pulau Industrial acquired using UAV TIR and RGB, and MOD11B2 data (1000 m resolution) from 10 February 2020 were used instead of 20 January 2020

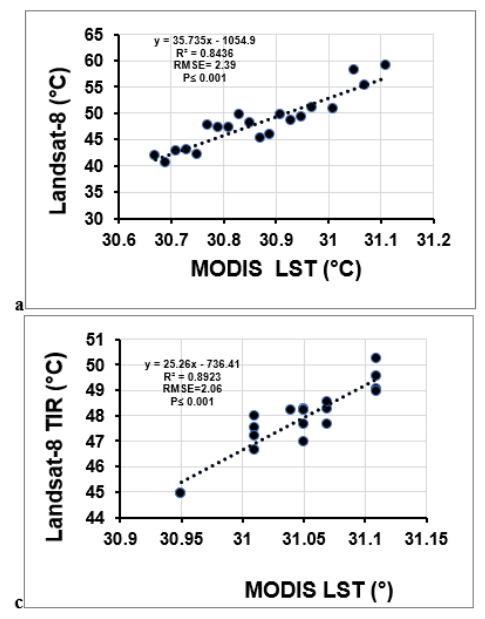

and Landsat-8 date for Passover (21st February 2020). There was precipitation or atmospheric disturbances between the acquisition dates of the UAV base, while there were low acquisition dates of the Landsat- 8 and MOD11B2 imageries. The spatial resolution of the thermal infrared band for MOD11B2 data is $1000 \mathrm{~m}$ and $100 \mathrm{~m}$ for Landsat-8 TIR data. Without any upscaling or downscaling of Landsat-8 data or MOD11B2 data, a high positive correlation of $\mathrm{R}^{2}$ $=0.84$ was obtained between the IHE values estimated from Landsat-8 TIR data and MOD11B2 data, and $\mathrm{R}^{2}=0.92$ was established between the IHE values estimated from Landsat- 8 data and UAV TIR data.

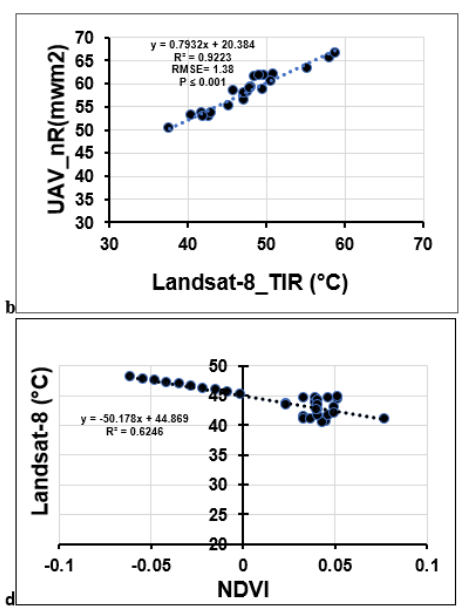

Figure 5. (a) Linear plots of retrieved IHE (a) MODIS LST (100 m) and Landsat-8 TIR (30 m) (b) Landsat-8 TIR (30 m) and UAV TIR (5 m) (c) MODIS LST (100 m) and Landsat-8 TIR (100 m (b) Landsat-8 TIR (30 m) and NDVI. 
The intensity of industrial area (IA) may be defined as the difference between the average temperature of IHE and non IHE (Table 4). In Pulau Indah, the threshold value of IHE is estimated at $>150{ }^{\circ} \mathrm{C}$ for the UAV and $>65{ }^{\circ} \mathrm{C}$ for Landsat- 8 TIR. For IHE in the study area, the standard deviation values of IHE show more variability than non-IHE. On average, the estimated mean IHE values of IA is $25.56^{\circ} \mathrm{C}$ more than the estimated mean IHE values of the surrounding area, respectively. However, the statistical model display shows the temperature variability within thin the industrial area. The map also provides the industrial heat base target along with some related energy use, and potential energy saving scale (Figure 5a.). In this context, we demonstrated the priority on thermal waste heat changes in Pulau Indah industrial area based on heat information. The highest significance is indicating red colour which is a high significance covered $2 \%$ has a great IHE value range (IHE $>75^{\circ} \mathrm{C}$ ). The second significance with yellow included $39 \%$ has an IHE value (IHE $<40^{\circ} \mathrm{C}$ ). While the third priority, indicating with the green colour consists of $32.88 \%$ has a heat value (IHE $<30{ }^{\circ} \mathrm{C}$ ). In Figure 6 the highest IHE was traced in the industrial area, which barren land was mostly found, and the lowest temperature is marked in the highly elevated areas with dense vegetation cover. Similarly, moderate temperatures are apprehending social collective from the environment and public amenities

Table 4. Summary of Industrial Waste Heat Statistics.

\begin{tabular}{llllll}
\hline $\begin{array}{l}\text { Extreme Hot } \\
\text { Target }\end{array}$ & $\begin{array}{l}\text { Temp } \\
\left({ }^{\circ} \mathbf{C}\right)\end{array}$ & Moderate Area & $\begin{array}{l}\text { Temp } \\
\left({ }^{\circ} \mathbf{C}\right)\end{array}$ & Cold Area & $\begin{array}{l}\text { Temp } \\
\left({ }^{\circ} \mathbf{C}\right)\end{array}$ \\
\hline Linde gas & 150 & Asphalt/Concrete & 43 & Grass land & 26 \\
Air Product & 75 & Air Tanks/Pipes & 35 & Vegetation & 24 \\
SSU Oleomas & 55 & Building/Roof & 28 & Water & 23 \\
\hline
\end{tabular}

Table.5 Statistical features of IHE values in the Pulau Indah industrial area.

\begin{tabular}{llllll}
\hline Class & Area & Percentage & Temp. & Heat range & Temp. \\
\hline Water Body & 4.244 & 17.734 & $14.35-23.93$ & very low & 23.93 \\
Coastal Area & 9.785 & 40.886 & $23.93-26.06$ & very low & 26.06 \\
Forest & 7.869 & 32.881 & $26.06-28.19$ & low & 28.19 \\
Greenness Area & 1.544 & 6.450 & $28.19-30.85$ & low & 30.85 \\
Industrial Area & 0.383 & 1.599 & $30.85-35.64$ & moderate low & 35.64 \\
Industrial Area & 0.075 & 0.314 & $35.65-43.10$ & moderate high & 43.1 \\
Factory & 0.023 & 0.097 & $43.10-54.81$ & high & 54.81 \\
Factory & 0.006 & 0.024 & $54.81-74.50$ & very hot & 74.5 \\
Chimney & 0.003 & 0.013 & $74.50-150.08$ & extremely hot & 150.08 \\
\hline
\end{tabular}

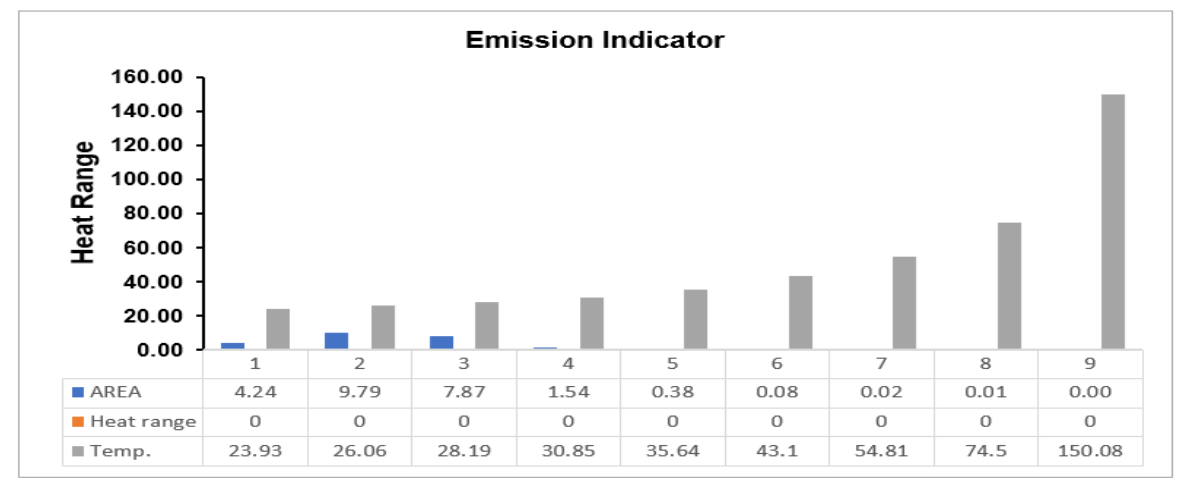

Figure 6. The histogram distribution of features classes in the Pulau Indah industrial area.

The three hottest target locations (Hot Spots) are clearly defined and characterized as three coloured targets (roof, asphalt) (Figure 5), with their accompanying colour-coded temperature values shown in Table 4. However, the Hot Spots are calculated for each source's emission, but only a few hot sources are shown in the above figures. This permits the industrial developers to evaluate whether a Hot target represents the chimney, outlet, or some other object of interest. Base on the result has shown that emission target (hot Spots) typically correspond to heat escaping from the chimney and boilers. Therefore, the emission sources zoomed area from the image, which provides visual evidence of the Hot Spot area. On the other hand, the industrial heat map (Figure 10), reveals that waste 
heat is released between the emission sources and the surrounding

features.

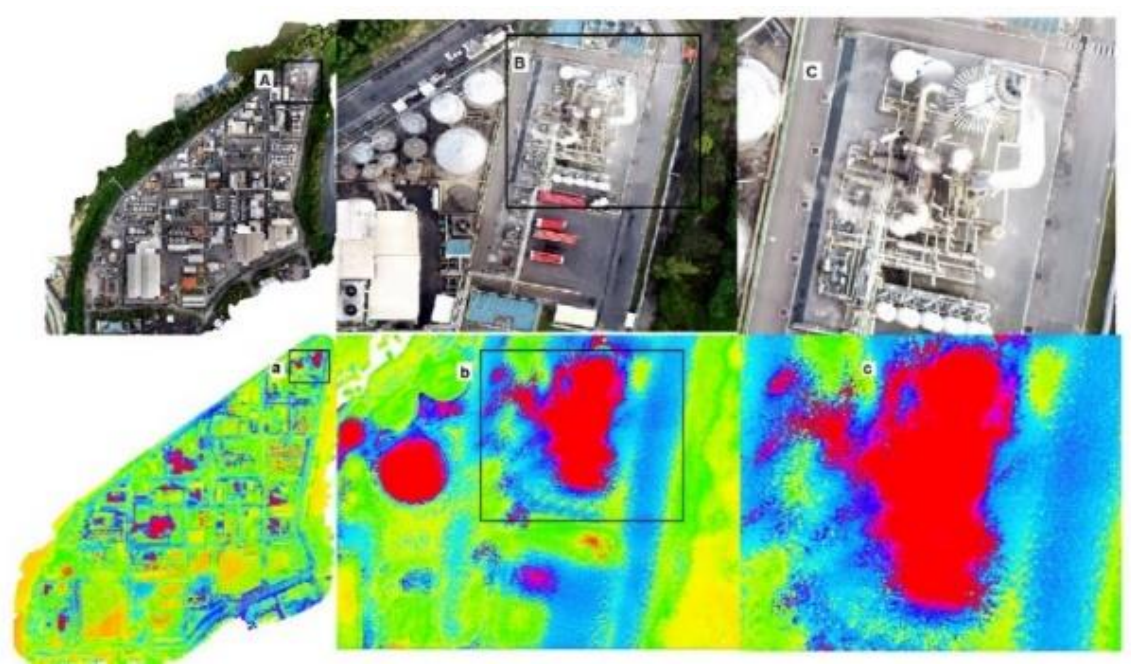

Figure 6. Complete View of the mosaic images Pulau Industrial area (A-C) is the RGB at $0.5 \mathrm{~m}$ resolution and (a-c) is the heat emission images at $<1 \mathrm{~m}$ resolution. The red is the Hotspot area (industrial boilers), The blues are the asphalt and concrete road within the industrial area.

To further assess the map, the industrial polygons overlaid on the corresponding UAV RGB as shown in Figure 6a, rather than in their current map shown in Figure 6b. As earlier been stated, all industrial temperature measurements above the ambient air temperature are measured as thermal waste heat. The sources target waste heat temperatures are not built on the attainment of the ambient temperature, which would only be the circumstance if the industries had a perfectly insulated living envelope and wellperforming attic ventilation.

\subsection{IHE identification}

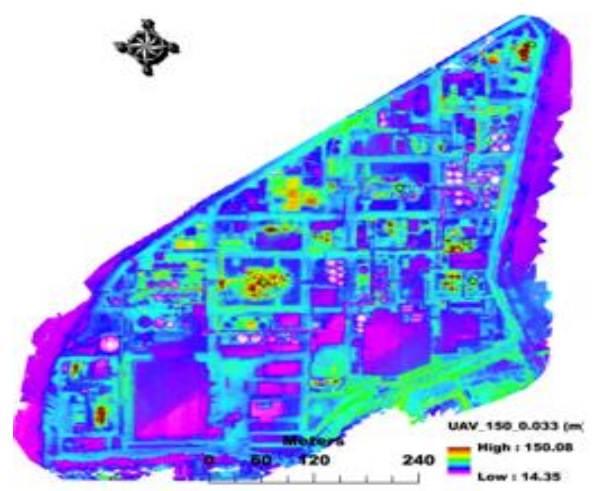

Some major heat source emissions can be easily distinguished as shown in Figure 5. The strong hotness of these classes was caused by an industrial emission and other artificial surfaces (asphalt, roof sheeting, etc.). Furthermore, surrounding features (empty land, sandstones) other features of IHE emissions from the industrial area and the bare land nearby has IHE $>35^{\circ} \mathrm{C}$, due to specific thermal properties and thermal inertia (Weng et al., 2004). IHE were more prevalent in hot source targets from industrial factories. The IHE was identified as an emission source with a threshold value $>100{ }^{\circ} \mathrm{C}$. As a result, parking lots, highways, power plants, and metal roofs are the best sites for IHE generation. Most of these hotspots have very little or no vegetation or water bodies.

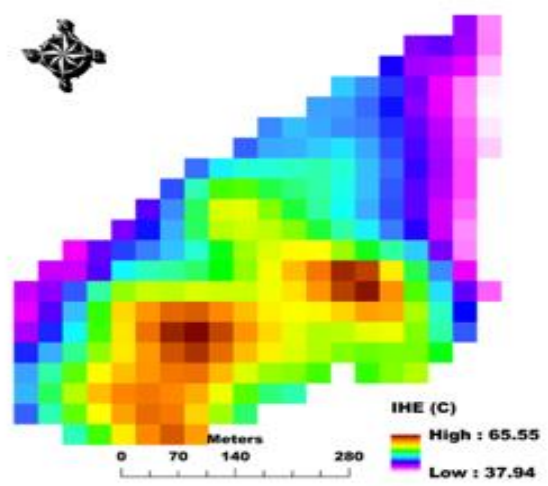

Figure 7. The retrieved Thermal imagery using (a) UAV TIR FLIR with (b) Landsat-8 TIR using the split-window algorithm of Pulau Industrial area.

Besides, when the bare land surface is exposed to solar radiation warms up very rapidly between 08:00 and 12:00, which contrasts with the urban and these areas significantly visible (Bendib et al., 2017). As well, the effect of 
Temperature on trees was attributed to two factors such as direct shading and evapotranspiration cooling (Oke, 1989)

\subsection{IHE downscaling using DisTrad model with different indices}

Thermal infrared (TIR) imagery is typically acquired at a coarser pixel resolution than shortwave sensors on the same satellite platform, and the TIR resolution is frequently insufficient for monitoring industrial heat emission (IHE) or the impacts of industrial estate development at finer spatial scales. As a result, thermal sharpening techniques are developed to sharpen TIR images to pixel resolutions in the shortwave band, which are frequently fine enough according to field-scale applications. TsHARP, a well-known thermal sharpening approach, employs a connection between LST and the NDVI, which was empirically derived at the TIR pixel resolution and utilized at the NDVI pixel resolution. Recent research shows that distinct connections between temperature and NDVI may exist only for a small subset of landscapes, such as those with predominantly green vegetation and uniform air and soil conditions. A unique data analysis sharpener (Normalized Difference Building Index (NDBI)) was evaluated to expand the applicability of thermal sharpening to a more complex area. Based on essential model characteristics, the NDBI approach provides a regression build-up area between TIR band brightness temperatures and shortwave spectral reflectance. A comparison of sharpening techniques used on an industrial area in Pulau Indah, an industrial park in Peninsular Malaysia, and a diverse natural landscape on Pulau Indah shows that the NDBI outperforms TsHARP in all conditions. While the NDBI technique can give high-resolution TIR images, the sharpening ratios that can be effectively applied are limited. Sharpening procedures, as a result, cannot substitute genuine thermal band imaging at precise resolutions.

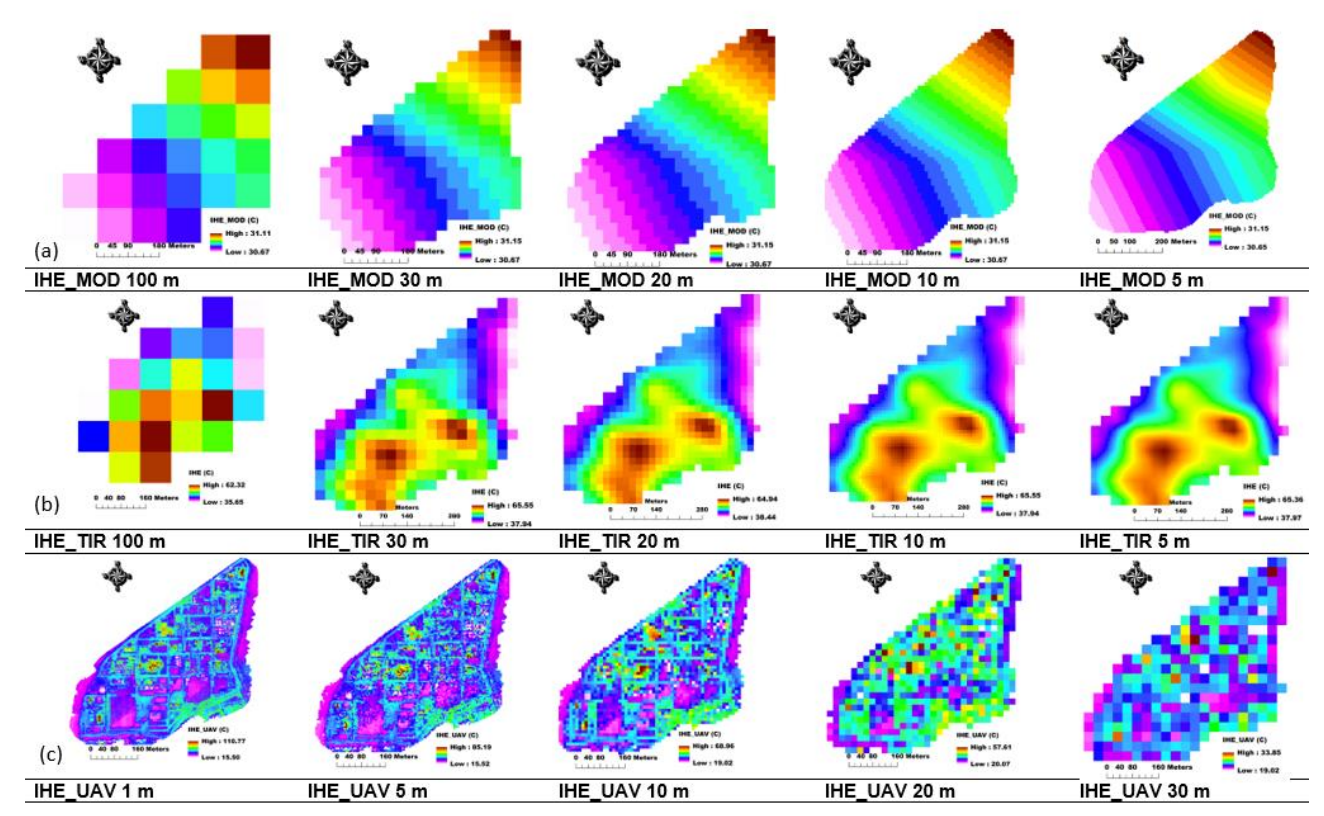

Figure 8. Applications of TsHARP to simulated (a) $1000 \mathrm{~m}$ data from MODIS LST data to 100, 30, 20 and $10 \mathrm{~m}$ (b) Landsat-8 TIR from 100, 30, 20 10, and $5 \mathrm{~m}$; (c) UAV TIR base from 0.03, 1, 5 10, 20 and 30 both acquired on 10 February 2020, 21th February 2020 and $20^{\text {th }}$ January 2020 in a subset area as shown in Table 1 . The reference temperatures (a-b) are displayed at a resolution of $30 \mathrm{~m}$ pixels. From 100 , 30, 20, 10, and $5 \mathrm{~m}$ pixel resolution, images from the original TsHARP were sharpened. The first column displays MODIS LST data, the second column Landsat-8 data, and the third column UAV TIR data.

\subsection{Assessment of Downscaling Results}

In context, the method being used was highlighted for retrieving heat emission from UAV TIR was compared with Landsat-8 and MODIS derived-LST, which covers entire Peninsular Malaysia daily in three MODIS thermal infrared bands $(29,31$, and 32) at a spectral resolution of $1000 \mathrm{~m}$ at nadir, and Landsat- 8 at a spectral resolution of $100 \mathrm{~m}$ at nadir resample to $30 \mathrm{~m}$ which spans from 3.66 to 14.28 microns. The images used in the study have different standards, with a spatial resolution of $1000 \mathrm{~m}$ for MODIS and $100 \mathrm{~m}$ for Landsat- 8 TIR. Therefore, MODIS data product with $1000 \mathrm{~m}$ resembled $100,30,20,10$, and $5 \mathrm{~m}$ respectively likewise 
Landsat- 8 with $100 \mathrm{~m}$ was resembled $30 \mathrm{~m}, 20 \mathrm{~m}, 10 \mathrm{~m}, 5 \mathrm{~m}$, and $1 \mathrm{~m}$ respectively and UAV TIR image was resembled $0.03,1,5$, 10,20 , and $30 \mathrm{~m}$ respectively before the integration using ArcGIS 10.5 software. Thus, the three heat emission distributions are reliable, the retrieved IHE range from UAV is $24.47^{\circ} \mathrm{C}$ to 150.08 ${ }^{\circ} \mathrm{C}$ with a mean of $25.7^{\circ} \mathrm{C}$, and Landsat- 8 is 37.95 to $65.51{ }^{\circ} \mathrm{C}$ with $53.82{ }^{\circ} \mathrm{C}$. Though, the retrieved MODIS LST values are far less than that of Landsat- 8 and UAV with the variation of $84.57{ }^{\circ} \mathrm{C}$,
Landsat -8 and MODIS with a variation of $36.74{ }^{\circ} \mathrm{C}$ (Landsat- 8 _IHE 37.95 to $65.51{ }^{\circ} \mathrm{C}$ and MOD_IHE $30.67{ }^{\circ} \mathrm{C}$ to $31.11^{\circ} \mathrm{C}$ ). This is attributed as a result of; (i) Existed time variation of $30 \mathrm{~min}$. between the sensors as well as a rapid flux in IHE of impervious surfaces caused by the high reflectivity from thermal objects,(ii) the contents of water vapour parameter in producing MODIS LST product IHE from $1000 \mathrm{~m}$ to $100 \mathrm{~m}$ results in the extend of a scaled effect (Yang et al., 2014).

Table. 6 The retrieve downscale values for the study location.

\begin{tabular}{cccccc}
\hline \multicolumn{5}{c}{ UAV TIR } \\
\hline $\mathbf{m}$ & Min & Max & Mean & Std & $\Delta$ Temp \\
\hline 100 & 23.23 & 29.83 & 25.40 & 1.52 & \\
30 & 19.02 & 33.85 & 25.7 & 1.84 & $-4.21 \sim 4.04$ \\
20 & 20.07 & 57.61 & 25.65 & 2.15 & $+1 \sim 23.76$ \\
10 & 19.02 & 68.96 & 25.62 & 1.97 & $-1 \sim 11.35$ \\
5 & 15.5 & 85.19 & 25.62 & 2.3 & $-3.52 \sim 16.23$ \\
1 & 15.5 & 110.77 & 25.56 & 2.28 & 25.58 \\
\hline \multicolumn{5}{c}{ Landsat-8 TIR } \\
\hline $\mathbf{m}$ & Min & Max & Mean & Std & $\Delta$ Temp \\
\hline 100 & 35.79 & 62.32 & 52.28 & 6.25 & \\
30 & 37.94 & 65.55 & 53.82 & 6.69 & $2.15 \sim 3.23$ \\
20 & 38.44 & 64.94 & 53.76 & 6.5 & $0.5 \sim-0.61$ \\
10 & 37.94 & 65.55 & 53.82 & 6.57 & $-0.5 \sim 0.61$ \\
5 & 37.97 & 65.36 & 53.82 & 6.56 & $0.3 \sim-0.19$ \\
1 & 37.95 & 65.55 & 53.82 & 6.56 & $-0.2 \sim 0.15$ \\
\hline \multicolumn{7}{c}{}
\end{tabular}

\begin{tabular}{cccccc}
\hline \multicolumn{5}{c}{ MODIS LST } \\
\hline $\mathrm{m}$ & Min & Max & Mean & Std & $\Delta$ Temp \\
\hline 100 & 30.67 & 31.11 & 30.87 & 0.13 & \\
30 & 30.67 & 31.15 & 30.91 & 0.14 & 0.04 \\
20 & 30.67 & 31.15 & 30.91 & 0.14 & 0 \\
10 & 30.67 & 31.15 & 30.91 & 0.14 & 0 \\
5 & 30.65 & 31.15 & 30.90 & 0.14 & $-0.2 \sim 0$ \\
\hline & & & & & \\
& & & NDVI & & \\
\hline $\mathrm{m}$ & Min & Max & Mean & Std & $\Delta$ Temp \\
\hline 30 & -0.0002 & 0.4744 & 0.102 & 0.084 & \\
20 & 0.0163 & 0.4565 & 0.106 & 0.078 & $0.0165 \sim-0.474$ \\
10 & 0.0221 & 0.458 & 0.106 & 0.075 & $0.0058 \sim 0.0015$ \\
5 & 0.0052 & 0.4603 & 0.106 & 0.079 & $-0.0169 \sim 0.0023$ \\
1 & 0.0001 & 0.4743 & 0.106 & 0.079 & $-0.0051 \sim 0.014$ \\
\hline
\end{tabular}

Figures 6 show IHE sharpening (b) from $100 \mathrm{~m}$ full resolution to $30,20,10$, and $5 \mathrm{~m}$ resolution. This is related to TIR sharpening for MODIS resolution photography at 1000, 100, 30, 20, 10, and $5 \mathrm{~m}$, which is a more challenging task. A significant aspect in using such a large sharpening ratio is generating representative homogenous samples because typical heat emission targets from industrial areas are often a sub-pixel at the MODIS LST resolution $(1000 \mathrm{~m})$. The homogenous pixel requirement (Equation 13) for generating TsHARP relationships is significantly simpler to achieve when sharpening Landsat-8 TIR data. This implies that there are enough representative samples to provide sufficient training sets. The sharpening tests were conducted solely for visual assessment. For comparison, the standard Landsat- 8 TIR thermal bands product The highest IHE values were mostly set up in the industrial hotspot sources. The greenest area covers the dominant part with $<30^{\circ} \mathrm{C}$, the industrial surrounding with $>30^{\circ} \mathrm{C}$, the factory sections with $>$ $50{ }^{\circ} \mathrm{C}$, and the heat sources above $100{ }^{\circ} \mathrm{C}$ as shown in table 5 . In disparity, the non-industrial area was set up with the minimum IHE of about $30.85{ }^{\circ} \mathrm{C}$. The correlation of industrial area and IHE

\subsection{Discussion}

An effective image sharpening scheme must bridge the gap between the industrial surrounding scale $(\mid 100 \mathrm{~m})$ and the target sources scale of interest (kilometers for the region PM). Here we examine an economical approach to downscale/upscaling, using a targeted emission sources disaggregation strategy. Variations are mapped across the industrial base on the area scales at $1 \mathrm{~m}$ to 1000 $\mathrm{m}$ resolution during industrial activities using high, medium, and coarse-scale remote sensing imagery from a platform like UAV,

was used in this study, which was resampled to a $30 \mathrm{~m}$ grid by the USGS data centre. Similarly, the UAV TIR imagery was aggregated to $0.03 \mathrm{~m}$ and then re-sampled to $1,5,10,20$, and $30 \mathrm{~m}$ using nearest neighbour techniques, matching data fields provided by Landsat- 8 TIR $(100 \mathrm{~m})$. In comparison to the original USGS LST data, the simulated TIR band sharpening tests for Landsat- 8 TIR sharpening (Figure 6b) result in well-defined field limits and consistent within-field variability in heat generation. However, there is a baseline temperature for validating the sharpening results, both techniques outperformed standard resampling methods visually, and the sharpening test ranged from 100 to $30 \mathrm{~m}$. (Figure $6)$.

distribution is expressed by the linear correlation Figure 4. The result indicates the relationship between NDVI and retrieved TIR IHE has a negative correlation, well corresponds with another report $[32,33]$ which indicate that the vegetation area was useful for decreasing IHE, there will be comfortability in an area with law IHE when compare with higher IHE.

Landsat, and MODIS data product. These medium and coarse-scale change estimates can then be spatially disaggregated to finer scales at sites of particular interest (e.g., industrial emission sources) using higher resolution imagery from the Land Remote Sensing Satellite (Landsat), the Moderate Resolution Imaging Spectroradiometer (MODIS), and high resolution like UAV data to interpret the large area, whenever such imagery is available (as determined by the satellite overpass schedule and cloud conditions). In this way, the temporal sampling power of the MODIS images for every 30 min can be combined with the spatial 
resolution of Landsat for every 16 days (100 m resamples to 30 and $1000 \mathrm{~m}$ for MODIS product). The disaggregation process serves both as a means for quantitatively validating the regional variation predictions and for examining complex emission sources of interest in greater detail, while the higher resolution imagery such as UAV

\section{CONCLUSION}

The thermal heat mapping for estimating IHE from Landsat-8 TIR data in the Pulau Indah industrial area has been successfully implemented. The thermal heat energy sources and other artificial surfaces (asphalt, roof sheeting) from the industrial plant from satellite sensors experienced high surface temperatures $\left(>65^{\circ} \mathrm{C}\right)$, with accuracy $\left(\mathrm{RMSE}= \pm 1.97{ }^{\circ} \mathrm{C}\right)$. Vegetated covered surfaces including neighboring greenness and coastal areas marked the lowest temperatures $\left(14 \sim 30{ }^{\circ} \mathrm{C}\right)$. The IHE of selected targets have been validated using in-situ observation apart from comparison with corresponding downscaled MODIS LST product (MOD11B2), For all of the downscaling algorithms, the NDVI has acted as the main supporting data for regression analysis. MODIS LST visual quality has enhanced, and earth surface object identification has improved as a result of the downscaling. MODIS LST data has been downscaled from $1000 \mathrm{~m}$ to $100 \mathrm{~m}$ using Landsat- 8 TIR $(30 \mathrm{~m})$ resolution with $\mathrm{R}^{2}=0.84$ and RMSE of 2.38 ${ }^{\circ} \mathrm{C}$, MODIS LST $100 \mathrm{~m}$ data using aggregated Landsat-8 TIR at $100 \mathrm{~m}$ resolution with $\mathrm{R}^{2}=0.89$ and RMSE of $2.06{ }^{\circ} \mathrm{C}$, and

\section{ACKNOWLEDGEMENT}

The authors wish to acknowledge the Ministry of Education Malaysia MRUN research grant (ref: PY/2019/02792), with vot number-RJ130000.7809.4L881 for this study. Facilities used at the Geoscience \& Digital Earth Centre (INSTEG) and the Department of Geoinformatics Universiti of Teknologi Malaysia is highly

\section{REFERENCES}

Algorithms, R., Models, E. and Implementation, T. (2020) 'Land Surface Temperature Retrieval from Landsat 5, 7 , and 8 over Rural Areas : Assessment of Di ff erent Retrieval Algorithms and Emissivity Models and Toolbox Implementation'.

At, P., Gudang, P., Gudang, P. and Takzim, J. D. (2015) 'Detailed Environmental Impact Assessment', (October).

Baena, S., Moat, J., Whaley, O. and Boyd, D. S. (2017) 'Identifying species from the air: UAVs and the very high resolution challenge for plant conservation', PLOS ONE, 12(11), pp. 1-21.

Bala, R., Prasad, R. and Pratap Yadav, V. (2019) 'Disaggregation of modis land surface temperature in urban areas using improved thermal sharpening techniques', Advances in Space Research. COSPAR, 64(3), pp. 591-602.

Barsi, J. A., Schott, J. R., Hook, S. J., Raqueno, N. G., Markham, B. L. and Radocinski, R. G. (2014) 'Landsat-8 thermal infrared sensor (TIRS) vicarious radiometric calibration', Remote Sensing, can be applied to upscaling processes which can serve as both as a means for quantitatively validating the regional variation predictions and for examining environmental warming.

Landsat- 8 TIR imagery $(30 \mathrm{~m})$ using aggregated UAV TIR at $5 \mathrm{~m}$ resolution with $\mathrm{R}^{2}$

Hence, the approach adopted manifests as a relatively simple yet robust method in mapping industrial area thermal heat energy sources. Hence, mapping, and monitoring of industrial heat emission to support understanding toward improving disparities on existing industrial substances for policymakers and industrial developers to draft policies and regulations for relevant industries, most significantly it will help in fast-tracking Target 9.4. and 11.6. to retrofit industries to make them sustainable, with increased resource-use efficiency and reduce the environmental impact of cities, by paying special attention to air quality and waste management in municipal by 2030 . Our findings indicate that in industrial areas characterized by a mixture of vegetated, paved, and unpaved surfaces, in contrast to NDVI, NDBI and NDSI can be effective as LST predictors in downscaling studies, particularly in industrial parks. This outcome is consistent with the previous research that utilized NDBI in addition to NDVI and other spectral indices as a downscaling factor and obtained lower RMSE than techniques that only used NDVI (Sharma et al., no date).

commendable for this study. The Earth Resources Observation System (EROS), the data centre of the united states geological survey (USGS), and the National Aeronautics and Space Administration (NASA) are also acknowledged for the satellite data provided for this paper.

6(11), pp. 11607-11626.

Bendib, A., Dridi, H. and Kalla, M. I. (2017) 'Contribution of Landsat 8 data for the estimation of land surface temperature in Batna city, Eastern Algeria', Geocarto International, 32(5), pp. 503-513.

Boesch, R. (2017) 'Thermal remote sensing with UAV-based workflows', International Archives of the Photogrammetry, Remote Sensing and Spatial Information Sciences - ISPRS Archives, 42(2W6), pp. 41-46.

Bromley, C., Ashraf, S. and Seward, A. (2015) 'Monitoring and Quantifying Heat Loss From Significant Monitoring and Quantifying Heat Loss From Significant', (November), pp. 3-10.

Burdun, I., Sagris, V. and Mander, Ü. (2019) 'Relationships between field-measured hydrometeorological variables and satellite-based land surface temperature in a hemiboreal raised bog', International Journal of Applied Earth Observation and Geoinformation. Elsevier, 74(May 2018), pp. 295-301. 
Casagli, N., Frodella, W., Morelli, S., Tofani, V., Ciampalini, A., Intrieri, E., Raspini, F., Rossi, G., Tanteri, L. and Lu, P. (2017) 'Spaceborne, UAV and ground-based remote sensing techniques for landslide mapping, monitoring and early warning', Geoenvironmental Disasters. Geoenvironmental Disasters, 4(1), pp. 1-23.

Chmaj, G. and Selvaraj, H. (2015) 'Distributed Processing Applications for UAV/drones: A Survey', Advances in Intelligent Systems and Computing, 1089, pp. 449-454.

Dahiru, M. Z. and Hashim, M. (2020) 'An Approach for the Retrieval of Land Surface Temperature from the Industrial Area Using Landsat-8 Thermal Infrared Sensors', IOP Conference Series: Earth and Environmental Science, 540(1).

Duan, S. B., Li, Z. L., Wang, C., Zhang, S., Tang, B. H., Leng, P. and Gao, M. F. (2019) 'Land-surface temperature retrieval from Landsat 8 single-channel thermal infrared data in combination with NCEP reanalysis data and ASTER GED product', International Journal of Remote Sensing. Taylor \& Francis, 40(5-6), pp. 1763 1778.

Energy, A. I. (2008) and Environmental Energy and Environmental.

Energy Commission (2017) 'Energy in Malaysia', Suruhanjaya Tenaga, 12

Fadhil, A. M. (2011) 'Drought mapping using Geoinformation technology for some sites in the Iraqi Kurdistan region', International Journal of Digital Earth, 4(3), pp. 239-257.

Ferrari, S., Maturilli, A., Carli, C., D’Amore, M., Helbert, J., Nestola, F. and Hiesinger, H. (2020) 'Thermal infrared emissivity of felsic-rich to mafic-rich analogues of hot planetary regoliths', Earth and Planetary Science Letters. Elsevier B.V., 534, p. 116089 .

Gillani, S. A., Rehman, S.-, Ahmad, H. H., Rehman, A., Ali, S., Junaid, U., Ahmad, A. and Ateeq, Z. (2019) 'Appraisal of Urban Heat Island over Gujranwala and its Environmental Impact Assessment using Satellite Imagery (1995-2016).', International Journal of Innovations in Science and Technology, 01(01).

goleman, daniel; boyatzis, Richard; Mckee, A. (2019) 'Peninsular Malaysia Electricity Supply Outlook 2017', Journal of Chemical Information and Modeling, 53(9), pp. 1689-1699.

Guha, S., Govil, H., Dey, A. and Gill, N. (2018) 'Analytical study of land surface temperature with NDVI and NDBI using Landsat 8 OLI and TIRS data in Florence and Naples city, Italy', European Journal of Remote Sensing. Taylor \& Francis, 51(1), pp. 667-678.

Harvey, M. C., Rowland, J. V. and Luketina, K. M. (2016) 'Drone with thermal infrared camera provides high resolution georeferenced imagery of the Waikite geothermal area, New Zealand', Journal of Volcanology and Geothermal Research. Elsevier B.V., 325, pp. 61-69.

Huo, H., Jiang, X., Song, X., Li, Z. L., Ni, Z. and Gao, C. (2014) 'Detection of coal fire dynamics and propagation direction from multi-temporal nighttime landsat SWIR and TIR data: A case study on the Rujigou Coalfield, Northwest (NW) China', Remote
Sensing, 6(2), pp. 1234-1259.

Jamei, Y., Rajagopalan, P. and Sun, Q. (Chayn) (2019) 'Spatial structure of surface urban heat island and its relationship with vegetation and built-up areas in Melbourne, Australia', Science of the Total Environment. Elsevier B.V., 659, pp. 1335-1351.

Jimenez-Munoz, J. C., Sobrino, J. A., Skokovic, D., Mattar, C. and Cristobal, J. (2014) 'Land surface temperature retrieval methods from landsat-8 thermal infrared sensor data', IEEE Geoscience and Remote Sensing Letters, 11(10), pp. 1840-1843.

Jos, O., Jos, A., Montes, R. and Lucas, Y. (2018) 'Downscaling of ASTER Thermal Images Based on Geographically Weighted Regression Kriging', pp. 1-20.

Khandelwal, S., Goyal, R., Kaul, N. and Mathew, A. (2018) 'Assessment of land surface temperature variation due to change in elevation of area surrounding Jaipur, India', Egyptian Journal of Remote Sensing and Space Science. National Authority for Remote Sensing and Space Sciences, 21(1), pp. 87-94.

Kumari, B., Tayyab, M., Shahfahad, Salman, Mallick, J., Khan, M. F. and Rahman, A. (2018) 'Satellite-Driven Land Surface Temperature (LST) Using Landsat 5, 7 (TM/ETM+ SLC) and Landsat 8 (OLI/TIRS) Data and Its Association with Built-Up and Green Cover Over Urban Delhi, India', Remote Sensing in Earth Systems Sciences. Remote Sensing in Earth Systems Sciences, 1(34), pp. 63-78.

Lee, S. M., Fernando, H. J. S., Princevac, M., Zajic, D., Sinesi, M., McCulley, J. L. and Anderson, J. (2003) 'Transport and diffusion of ozone in the nocturnal and morning planetary boundary layer of the Phoenix valley', Environmental Fluid Mechanics, 3(4), pp. 331-362.

Liu, Y., Hu, C., Zhan, W., Sun, C., Murch, B. and Ma, L. (2018) 'Identifying industrial heat sources using time-series of the VIIRS Nightfire product with an object-oriented approach', Remote Sensing of Environment. Elsevier, 204(October 2017), pp. $347-$ 365 .

Malik, M. S., Shukla, J. P. and Mishra, S. (2019) 'Relationship of LST, NDBI and NDVI using landsat- 8 data in Kandaihimmat watershed, Hoshangabad, India', Indian Journal of Geo-Marine Sciences, 48(1), pp. 25-31.

Mia, M. B., Fujimitsu, Y. and Nishijima, J. (2017) 'Thermal Activity Monitoring of an Active Volcano Using Landsat 8/OLITIRS Sensor Images: A Case Study at the Aso Volcanic Area in Southwest Japan', Geosciences (Switzerland), 7(4).

Mukherjee, S., Joshi, P. K. and Garg, R. D. (2015) 'Evaluation of LST downscaling algorithms on seasonal thermal data in humid subtropical regions of India', International Journal of Remote Sensing, 36(10), pp. 2503-2523.

Nguyen, Q. K., Trinh, L. H., Dao, K. H. and Dang, N. D. (2019) 'Land Surface Temperature Dynamics In Dry Season 2015-2016 According To Landsat 8 Data In The South-East Region of Vietnam', Geography, Environment, Sustainability, 12(1), pp. 7587

Nikolic, J., Burri, M., Rehder, J., Leutenegger, S., Huerzeler, C. and Siegwart, R. (2013) 'A UAV system for inspection of industrial 
facilities', IEEE Aerospace Conference Proceedings. IEEE.

Oke, T. R. (1989) 'The micrometeorology of the urban forest', Philosophical Transactions - Royal Society of London, B, 324(1223), pp. 335-349.

Piikki, K. and Söderström, M. (2019) 'Digital soil mapping of arable land in Sweden - Validation of performance at multiple scales', Geoderma. Elsevier, 352(October 2017), pp. 342-350.

Pour, A. B., Hashim, M., Hong, J. K. and Park, Y. (2019) 'Lithological and alteration mineral mapping in poorly exposed lithologies using Landsat- 8 and ASTER satellite data: Northeastern Graham Land, Antarctic Peninsula', Ore Geology Reviews. Elsevier B.V., 108, pp. 112-133.

Pour, A. B., Hashim, M., Makoundi, C. and Zaw, K. (2016) 'Structural Mapping of the Bentong-Raub Suture Zone Using PALSAR Remote Sensing Data, Peninsular Malaysia: Implications for Sediment-hosted/Orogenic Gold Mineral Systems Exploration', Resource Geology, 66(4), pp. 368-385.

Rani, M., Kumar, P., Chandra, P., Srivastava, P. K., Chaudhary, B. S., Tomar, V. and Prasad, V. (2018) 'Remote Sensing Applications : Society and Environment Multi-temporal NDVI and surface temperature analysis for Urban Heat Island inbuilt surrounding of sub-humid region: A case study of two geographical regions', Remote Sensing Applications: Society and Environment. Elsevier B.V., 10(November 2017), pp. 163-172.

Ren, H., Du, C., Qin, Q., Liu, R., Meng, J. and Li, J. (2014) 'Atmospheric water vapor retrieval from Landsat 8 and its validation', International Geoscience and Remote Sensing Symposium (IGARSS). IEEE, pp. 3045-3048.

Rogers, A. S. and Kearney, M. S. (2004) 'Reducing signature variability in unmixing coastal marsh Thematic Mapper scenes using spectral indices', International Journal of Remote Sensing, 25(12), pp. 2317-2335.

Sekertekin, A. and Bonafoni, S. (2020) 'Land Surface Temperature Retrieval from Landsat 5, 7, and 8 over Rural Areas: Assessment of Different Retrieval Algorithms and Emissivity Models and Toolbox Implementation', Remote Sensing, 12(2), p. 294.

Sharma, K. V., Khandelwal, S. and Kaul, N. (no date) Downscaling of Coarse Resolution Land Surface Temperature Through Vegetation Indices Based Regression Models. Springer Singapore.

Shumilo, L., Yailymov, B., Kussul, Lavreniuk, M., Shelestov, A. and Korsunska, Y. (2019) 'Land surface temperature analysis and trends for Rivne using remote sensing data', 2019 IEEE 2nd Ukraine Conference on Electrical and Computer Engineering, UKRCON 2019 - Proceedings. IEEE, pp. 1107-1111.

Smith, J. A. (1997) 'Remote sensing of land surface temperature: the directional viewing effect', IEEE Transactions on Geoscience and Remote Sensing, 35(4), pp. 972-974.

Syafrina, A. H., Zalina, M. D. and Juneng, L. (2015) 'Historical trend of hourly extreme rainfall in Peninsular Malaysia', Theoretical and Applied Climatology, 120(1-2), pp. 259-285.

Takebayashi, H. (2017) 'Influence of urban green area on air temperature of surrounding built-up area', Climate, 5(3).
Tan, K., Liao, Z., Du, P. and Wu, L. (2017) 'Land surface temperature retrieval from Landsat 8 data and validation with geosensor network', Frontiers of Earth Science, 11(1), pp. 20-34.

Tang, K. H. D. (2019) 'Climate change in Malaysia: Trends, contributors, impacts, mitigation and adaptations', Science of the Total Environment. Elsevier B.V., 650, pp. 1858-1871.

Torres-rua, A. F. and Hipps, L. (2019) 'Estimation of Surface Thermal Emissivity in a Vineyard for UAV Microbolometer Thermal Cameras Using NASA HyTES Hyperspectral Thermal, and Landsat and AggieAir Optical Data', 1100802(May).

Turner, D., Lucieer, A., Malenovský, Z., King, D. H. and Robinson, S. A. (2014) 'Spatial co-registration of ultra-high resolution visible, multispectral and thermal images acquired with a micro-UAV over antarctic moss beds', Remote Sensing, 6(5), pp. $4003-4024$

Veefkind, P., van Oss, R. F., Eskes, H., Borowiak, a, Dentner, F. and Wilson, J. (2007) 'The Applicability of Remote Sensing in the Field of Air Pollution', Framework, pp. 1-54.

Vollath, D. (1987) 'Automatic focusing by correlative methods', Journal of Microscopy, 147(3), pp. 279-288.

Wang, G., Gertner, G. and Anderson, A. B. (2004) 'Up-scaling methods based on variability-weighting and simulation for inferring spatial information across scales', International Journal of Remote Sensing, 25(22), pp. 4961-4979.

Wang, L. J., Guo, M., Sawada, K., Lin, J. and Zhang, J. (2015) 'Landslide susceptibility mapping in Mizunami City, Japan: A comparison between logistic regression, bivariate statistical analysis and multivariate adaptive regression spline models', Catena. Elsevier B.V., 135, pp. 271-282.

Weng, Q., Lu, D. and Schubring, J. (2004) 'Estimation of land surface temperature-vegetation abundance relationship for urban heat island studies', Remote Sensing of Environment, 89(4), pp. 467-483.

Wu, Jinhua, Zhong, B., Tian, S., Yang, A. and Wu, Junjun (2019) 'Downscaling of Urban Land Surface Temperature Based on Multi-Factor Geographically Weighted Regression', IEEE Journal of Selected Topics in Applied Earth Observations and Remote Sensing. IEEE, 12(8), pp. 2897-2911.

Wulder, M. A., Loveland, T. R., Roy, D. P., Crawford, C. J., Masek, J. G., Woodcock, C. E., Allen, R. G., Anderson, M. C., Belward, A. S., Cohen, W. B., Dwyer, J., Erb, A., Gao, F., Griffiths, P., Helder, D., Hermosilla, T., Hipple, J. D., Hostert, P., Hughes, M. J., Huntington, J., Johnson, D. M., Kennedy, R., Kilic, A., Li, Z., Lymburner, L., McCorkel, J., Pahlevan, N., Scambos, T. A., Schaaf, C., Schott, J. R., Sheng, Y., Storey, J., Vermote, E., Vogelmann, J., White, J. C., Wynne, R. H. and Zhu, Z. (2019) 'Current status of Landsat program, science, and applications', Remote Sensing of Environment, 225(November 2018), pp. 127 147.

Yang, L., Cao, Y. G., Zhu, X. H., Zeng, S. H., Yang, G. J., He, J. Y. and Yang, X. C. (2014) 'Land surface temperature retrieval for arid regions based on Landsat-8 TIRS data: A case study in Shihezi, Northwest China', Journal of Arid Land, 6(6), pp. 704-716. 
Yao, H., Qin, R. and Chen, X. (2019) 'Unmanned aerial vehicle for remote sensing applications - A review', Remote Sensing, 11(12), pp. 1-22.

Zawadzka, J., Corstanje, R., Harris, J. and Truckell, I. (2019) 'Downscaling Landsat-8 land surface temperature maps in diverse urban landscapes using multivariate adaptive regression splines and very high resolution auxiliary data', International Journal of Digital Earth. Taylor \& Francis, 0(0), pp. 1-16.

Zawadzka, J., Corstanje, R., Harris, J., Truckell, I., Zawadzka, J., Corstanje, R., Harris, J., Truckell, I., Corstanje, R., Harris, J. and Truckell, I. (2019) 'Downscaling Landsat-8 land surface temperature maps in diverse urban landscapes using multivariate adaptive regression splines and very high resolution auxiliary data and very high resolution auxiliary data', International Journal of Digital Earth. Taylor \& Francis, 0(0), pp. 1-16.

Zha, Y., Gao, J. and Ni, S. (2003) 'Use of normalized difference built-up index in automatically mapping urban areas from TM imagery', International Journal of Remote Sensing, 24(3), pp. 583594.
Zhang, P., Yuan, C., Sun, Q., Liu, A., You, S., Li, X., Zhang, Y., Jiao, X., Sun, D., Sun, M., Liu, M. and Lun, F. (2019) 'SatelliteBased Detection and Characterization of Industrial Heat Sources in China', Environmental Science and Technology, 53(18), pp. 11031-11042.

Zhao, H. and Chen, X. (2005) 'Use of normalized difference bareness index in quickly mapping bare areas from TM/ETM+', International Geoscience and Remote Sensing Symposium (IGARSS), 3(December 2017), pp. 1666-1668.

Zhao, W., Wu, H., Yin, G. and Duan, S. B. (2019) 'Normalization of the temporal effect on the MODIS land surface temperature product using random forest regression', ISPRS Journal of Photogrammetry and Remote Sensing. Elsevier, 152(April), pp. 109-118.

Zhou, Y., Zhang, L., Xiao, J., Williams, C. A., Vitkovskaya, I. and Bao, A. (2019) 'Spatiotemporal transition of institutional and socioeconomic impacts on vegetation productivity in Central Asia over last three decades', Science of the Total Environment. Elsevier B.V., 658, pp. 922-935. 